\title{
Time-dependent wettability changes on plasma-treated surfaces of unmodified and thermally modified European beech wood
}

\author{
D. Altgen ${ }^{1,2} \cdot$ M. Altgen ${ }^{2} \cdot$ S. Kyyrö ${ }^{2} \cdot$ L. Rautkari ${ }^{2} \cdot$ C. Mai ${ }^{1}$
}

Received: 11 July 2019 / Published online: 4 February 2020

(c) The Author(s) 2020

\begin{abstract}
The wettability of a freshly cut wood surface will change over time, which is denoted as natural ageing. Water contact angle measurements indicated that the thermal modification of European beech reduces its wettability, but does not affect the rate at which the contact angle increases within a 4-week period. A plasma treatment of fresh wood surfaces enhanced the wettability and equaled the wettability properties of unmodified and thermally modified wood surfaces. The contact angle on plasma-treated wood surfaces increased faster than on unmodified wood surfaces, but a reduction in contact angle by the plasma treatment was still evident after ageing for 4 weeks.
\end{abstract}

\section{Introduction}

A freshly cut wood surface is one requirement to achieve sound coating and gluing abilities (Nussbaum 1999). With aging of wood, the surface becomes less active, which affects the performance of coatings and adhesive systems. The causes of the aging effect are not yet fully understood, but one of the key factors might be the migration of wood extractives from the interior to the wood. This results in poor wetting properties with water, assessed by contact angle measurements, as the surface becomes more hydrophobic. An air plasma treatment enhances the wetting properties of various wood species with water (Altgen et al. 2016a). The plasma effect on wood is not permanent, as the treated surface will also age. Contact angle measurements indicated that the rate of inactivation of plasma-treated wood surfaces depends on the plasma process parameters (Riedl et al. 2014), and XPS measurements showed that the rate can be higher than the natural inactivation process (Avramidis et al. 2016). Thermal modification of wood has the opposite effect: it reduces the wettability of wood with water. In

C. Mai

cmai@gwdg.de

1 Faculty of Forest Science and Forest Ecology, Wood Biology and Wood Products, Georg-August University Göttingen, Büsgenweg 4, 37077 Göttingen, Germany

2 Department of Bioproducts and Biosystems, School of Chemical Engineering, Aalto University, P.O. Box 11000, 00076 Aalto, Finland addition, there is evidence that the decrease in contact angle by ageing proceeds at a lower rate compared to unmodified wood (Altgen and Militz 2017). Plasma treatment strongly affects thermally modified wood, whereupon the difference in water contact angle and surface free energy between unmodified and thermally modified wood surfaces can fully diminish depending on the treatment intensity (Altgen et al. 2016a). However, it is unknown whether the disappearance of the plasma effect due to ageing is different from that on unmodified wood.

The objective of this study was to analyze the effect of thermal modification and plasma treatment on the timedependent change in wettability caused by ageing of European beech wood. Wettability changes were assessed by measuring the contact angle of water at different time intervals after storing the samples under constant climatic conditions.

\section{Materials and methods}

\subsection{Material}

European beech (Fagus sylvatica L.) wood that originated from the same $\log$ was used for the experiment. A total of 20 slats with dimensions of $25 \times 30 \times 450 \mathrm{~mm}^{3}$ (thickness $\times$ width $\times$ length) were prepared from kiln-dried boards. The growth rings were oriented $45^{\circ}$ to the radial surface. 


\section{Thermal modification}

Half of the slats were thermally modified on a laboratory scale in a closed reactor system. The treatment, including the heating rates and the treatment steps, was identical to the proceeding described in Altgen et al. (2016b). The slats were treated at a maximum temperature of $170{ }^{\circ} \mathrm{C}$ for $3 \mathrm{~h}$ under nearly saturated water vapor conditions, which resulted in a maximum pressure of $0.78 \mathrm{MPa}$.

\subsection{Plasma treatment}

$1 \mathrm{~h}$ before the plasma treatment and the first contact angle measurements, all slats were planed to a thickness of $5 \mathrm{~mm}$ to create a fresh surface. Each slat was cut into five samples of $5 \times 30 \times 80 \mathrm{~mm}^{3}$ (thickness $\times$ width $\times$ length). Half of these samples remained untreated, while the other half was plasma-treated. The plasma treatment involved a direct dielectric discharge setup using compressed air as process gas, an alternating voltage of $23 \mathrm{kV}$ and a treatment time of $1 \mathrm{~s}$, according to the parameter settings described in Altgen et al. (2016a).

\subsection{Contact angle measurements}

Contact angle measurements were taken directly after planing and plasma treatment. These measurements were repeated on separate sample sets after 2, 13 and 27 days. The samples were stored at $20{ }^{\circ} \mathrm{C}$ and $65 \% \mathrm{RH}$. One sample per slat was used for each measurement, which refers to 5 samples per variant. The contact angle of deionized water was recorded following the sessile drop technique by using a Krüss G10 measurement system in connection with the corresponding Krüss DSA 1 software (Krüss GmbH, Hamburg, Germany). A volume of $10 \mu \mathrm{l}$ was applied to the sample surface, and the contact angle was recorded with 25 frames per second and a total of 250 frames. Five measurements per sample were taken, resulting in 25 measurements per variable (modification process and time). The contact angle was determined as constant wetting rate angle (CWRA) using the differential method described by Nussbaum (1999).

\subsection{Analysis of chemical composition}

After contact angle measurement, the samples were milled in a Wiley mill to pass through a 30 mesh screen. About $2 \mathrm{~g}$ of wood particles was extracted in a Soxhlet apparatus with $200 \mathrm{ml}$ acetone for $8 \mathrm{~h}$. The determination of carbohydrates and lignin was performed in triplicate on the extracted samples according to the analytical procedure (NREL/TP-51042618) issued by the U.S. National Renewable Energy Laboratory. The ash content was determined according to TAPPI 211 on- 02 by exposing oven-dried samples to $525^{\circ} \mathrm{C}$ for $5 \mathrm{~h}$.

\section{Results and discussion}

The thermal modification of beech wood resulted in a mass loss of about $17 \%$. It should be noted that some acetonesoluble degradation products additionally accumulated in the wood (emerged as extractives, Table 1). The mass loss was mostly caused by the degradation of the cell wall carbohydrates, as was evidenced by the decrease in holocellulose content and the increase in lignin content of the solid residue (Table 1). The removal of carbohydrates, mainly hemicelluloses, is accompanied by a loss in hydroxyl-groups that may form hydrogen bonds with water molecules. Lignin, on the other hand, is less hygroscopic. Thus, the changes in chemical composition are well in line with the increase in the contact angle on fresh surfaces from $58^{\circ}$ to $74^{\circ}$ due to thermal modification (Gérardin et al. 2007).

In contrast to thermal modification, the plasma treatment led to a strong reduction in the contact angle. Interestingly, the contact angle of the reference and the thermally modified wood was nearly the same after plasma treatment, reaching $25^{\circ}$ and $23^{\circ}$, respectively (Fig. 1a). This significant decrease in contact angle verifies the strong effect of the plasma-treatment on thermally modified surfaces that has been observed previously (Altgen et al. 2016a). The high lignin content in the thermally modified material might enhance the generation of oxygen-containing groups on the wood surface, because lignin is more susceptible to oxidation by a plasma treatment than the polysaccharides (Klarhöfer et al. 2010).

Table 1 Mass loss due to thermal modification (\%) and chemical composition (\%) of unmodified (Ref) and thermally modified (Thermo) beech wood

\begin{tabular}{lllllll}
\hline Sample & Mass loss & Extractives & Ash & Insoluble lignin & Soluble lignin & Holocellulose \\
\hline Ref & - & 2.4 & $0.5(0.1)$ & $24.1(1.0)$ & $3.2(0.1)$ & $72.8(1.6)$ \\
Thermo & $16.8(1.0)$ & 10.1 & $0.8(0.4)$ & $37.3(1.6)$ & $1.9(0.1)$ & $56.3(1.9)$ \\
\hline
\end{tabular}

Standard deviations are shown in parentheses 


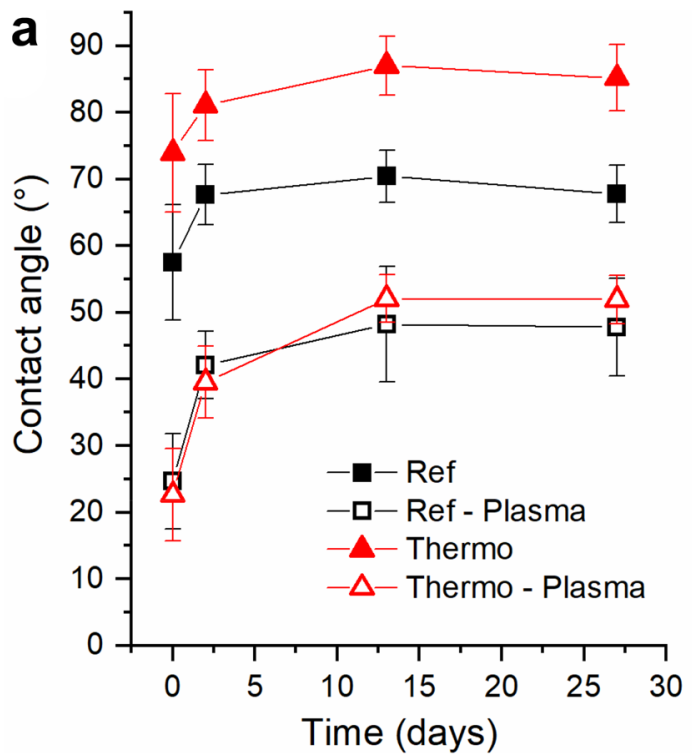

Fig. 1 Changes in water contact angles by surface ageing: a changes in the contact angle in the course of 27 days of storage. b Comparison of the contact angle changes caused by thermal modification and

Ageing during storage at constant climatic conditions $\left(20{ }^{\circ} \mathrm{C}\right.$ and $\left.65 \% \mathrm{RH}\right)$ resulted in an increase in the contact angles (Fig. 1a). The increase in contact angle was nonlinear, with a steep slope from day 0 to day 2 and no further increase from day 13 to day 27 . The rate at which the contact angle increased over time was nearly identical for the reference and the thermally modified wood; thus, the contact angle continued to be ca. 30\%-points larger on thermally modified wood even after day 27 (Fig. 1b). This is in contrast to the results of Altgen and Militz (2017), who found less increase in the contact angle due to ageing for thermally modified wood. The authors, however, took their measurements on Norway spruce and Scots pine, which differed also in the contact angle measured on fresh surfaces.

The increase in contact angle due to ageing proceeded faster on plasma-treated samples (Fig. 1a), which is in line with previous XPS studies (Avramidis et al. 2016). There was, however, no further increase in the contact angle from day 13 to day 27, even though the contact angle of the plasma-treated surfaces was still lower than the contact angle of the fresh reference surface. Furthermore, the ageing of the reference and the thermally modified wood was almost identical after plasma treatment. The increase in contact angle from day 0 to day 27 was only slightly higher for thermally modified wood $(+20 \%$-points $)$ than for the reference $(+18 \%)$ (Fig. 1b).

The equal surface wettability in contact with water of thermally modified and unmodified samples after plasma treatment over a period of at least four weeks reflects the benefits of the treatment for wood gluing or coating

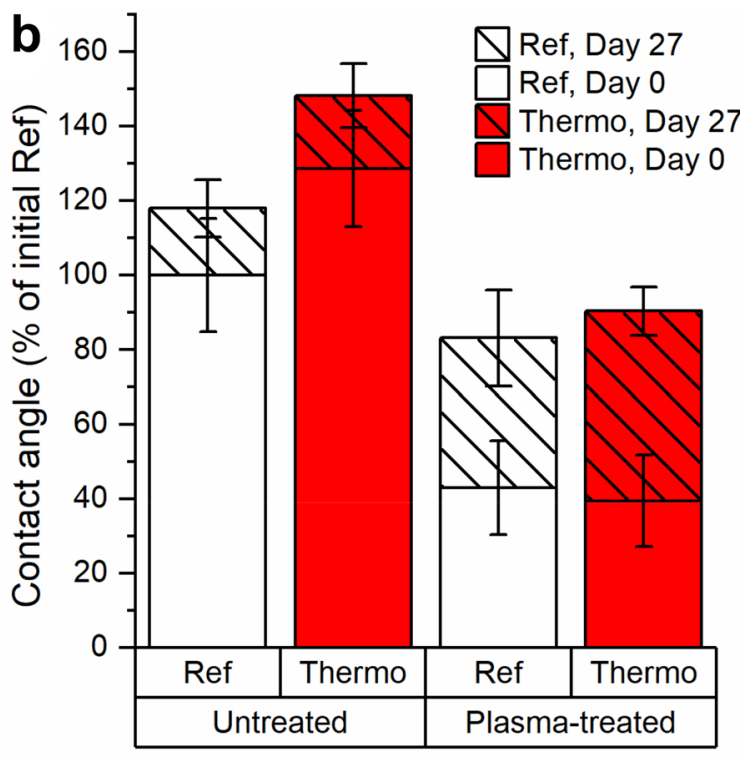

plasma treatment for day 0 and day 27 . The average contact angle of the untreated reference samples at day 0 was set to $100 \%$ in $\mathbf{b}$

applications, i.e. if modified and unmodified wood is used in a material mix. One example for such a mixture would be the use of recycled thermally modified wood among unmodified particles for the production of wood-based composites, such as particleboards.

\section{Conclusion}

The use of contact angle measurements to compare the aging behavior of both thermally modified and plasma treated wood showed that:

- The thermal modification increased the contact angle but did not change the rate of aging of the surface.

- The plasma treatment reduced the contact angles of unmodified and thermally modified surfaces. Both surfaces reached the same contact angle and showed the same aging behavior over a period of 4 weeks.

- Plasma-treated surfaces showed a faster process of surface ageing than untreated surfaces but did not reach the contact angle of freshly cut surfaces even after 4 weeks of ageing.

Acknowledgements Open Access funding provided by Projekt DEAL. This work was supported by the FNR (Fachagentur für nachwachsende Rohstoffe), Support code 22005410. The authors would like to thank Georg Avramidis, for the plasma treatment of the wood particles. 
Open Access This article is licensed under a Creative Commons Attribution 4.0 International License, which permits use, sharing, adaptation, distribution and reproduction in any medium or format, as long as you give appropriate credit to the original author(s) and the source, provide a link to the Creative Commons licence, and indicate if changes were made. The images or other third party material in this article are included in the article's Creative Commons licence, unless indicated otherwise in a credit line to the material. If material is not included in the article's Creative Commons licence and your intended use is not permitted by statutory regulation or exceeds the permitted use, you will need to obtain permission directly from the copyright holder. To view a copy of this licence, visit http://creativecommons.org/licenses/by/4.0/.

\section{References}

Altgen M, Militz H (2017) Thermally modified Scots pine and Norway spruce wood as substrate for coating systems. J Coat Technol Res 14:531-541. https://doi.org/10.1007/s11998-016-9871-8

Altgen D, Avramidis G, Viöl W, Mai C (2016a) The effect of air plasma treatment at atmospheric pressure on thermally modified wood surfaces. Wood Sci Technol 50:1227-1241. https://doi. org/10.1007/s00226-016-0856-7

Altgen M, Willems W, Militz H (2016b) Wood degradation affected by process conditions during thermal modification of European beech in a high-pressure reactor system. Eur J Wood Prod 74(5):653662. https://doi.org/10.1007/s00107-016-1045-y

Avramidis G, Wascher R, Militz H, Viöl W (2016) Impact of air-plasma treatment at atmospheric pressure on wood and wood extractives. Int Wood Prod J 7:76-79. https://doi.org/10.1080/20426 445.2016.1162429

Gérardin P, Petrič M, Petrissans M, Lambert J, Ehrhrardt JJ (2007) Evolution of wood surface free energy after heat treatment. Polym Degrad Stab 92:653-657. https://doi.org/10.1016/j.polymdegra dstab.2007.01.016

Klarhöfer L, Viöl W, Maus-Friedrichs W (2010) Electron spectroscopy on plasma treated lignin and cellulose. Holzforschung 64:331336. https://doi.org/10.1515/hf.2010.048

Nussbaum RM (1999) Natural surface inactivation of Scots pine and Norway spruce evaluated by contact angle measurements. Holz Roh Werkst 57:419-424. https://doi.org/10.1007/s001070050067

Riedl B, Angel C, Pregent J, Blanchet P, Stafford L (2014) Effect of wood surface modification by atmospheric-pressure plasma on waterborne coating adhesion. BioResources 9:4908-4923

Publisher's Note Springer Nature remains neutral with regard to jurisdictional claims in published maps and institutional affiliations. 